\title{
FACTORS AFFECTING LEARNING DISABILITIES IN MATHEMATICS: A STUDY OF CENTRAL REGION OF NEPAL
}

\author{
Dr. Ramjee Prasad Pandit
}

\begin{abstract}
The students whose achievement lagged behind their intellectual potential presents a serious problem to the parents, society and finally to the nation; instead of being the contributing members they turn out to be social problem and get involved in the most common social malaise-student on rest. Describing groups who have average or above average intelligence continuously failing to maintain normal progress in school subjects as learning disabled students, the teacher education programs in western countries like U.S.A. and Europe started the identification, diagnosis and serve them since 1963. But in developing countries, for example, in Nepal and India, although the efforts are directed towards this direction, no the considerable progress has yet been observed. So the present investigation was concerned with the identification of the causes of primary school children learning disabilities in mathematics (CLDM). 58 LD boys and 46 LD girls from 29 rural and 15 urban schools situated in different parts of central region of Nepal participated in this study. The analysis of these 104 LD students' bio-data revealed that the factors related to the children with learning disabilities in mathematics were the poor instruction, parents' adverse behavior to them, teacher's negligence in the class. It was suggested that the quality of teaching strategies and quality of instruction in the schools must be improved. Further research is needed for the generalization of the findings throughout the nation.
\end{abstract}

\section{INTRODUCTION}

Students population in primary schools consist of students having different levels of intelligence and vary accordingly in their level of performance in mathematics. On the one hand we find children whose academic achievement is commensurate with their intelligence, i.e. there is not significance, discrepancy between their ability and achievement. On the other hand, there are others who have average or above average intelligence but they continuously fail to maintain normal progress in school subjects e.g. mathematics. In fact, in later group, there are some students who have a significant discrepancy between their ability and achievement. Since these children are apparently normal with no sign of any physical, mental and other disability, they often elude traditional categorization of exceptionality. The term 'Learning Disabilities (LDs)' emerged from a need to identify and serve this later group of children. The term learning disabilities was first coined by Samual Kirk in 1963 to describe children who have serious learning problems in schools but do not fall under other categories of handicap. 


\section{FACTORS AFFECTING LEARNING DISABILITIES}

What prompted the birth of this newest area in special education was the realization that many children with learning problems were simply not receiving needed educational services. By recognizing this group as LDs, the teacher education programs in USA and Europe started the identification, diagnosis and serve these children. But the developing countries like Nepal who might have such group of students having learning problems are not still acquainted with this concept. Who might have such group of students having learning problems are not still acquainted with this concept.

There is no universally accepted definition of learning disabilities. However, most definitions incorporate three criteria that must be met for a child to be labeled learning disabled. (a) Learning disabled children must have a significant discrepancy between his potential and or ability and actual achievement. (b) Learning disabled children must have learning problems that cannot be attributed to other handicapping condition, such as blindness or mental retardation. (c) Learning disabled children must need special educational services to succeed, service that are not needed by their non-handicapped peers. Hallahan and Kauffman, (1976) define as a learning disabled child is one who is not achieving up his potential. Learning disabilities in mathematics has been defined as:

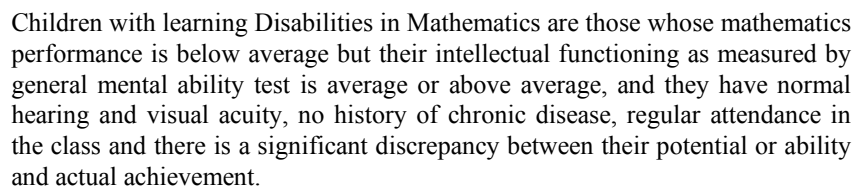

Children with learning Disabilities in Mathematics are those whose mathematics performance is below average but their intellectual functioning as measured by general mental ability test is average or above average, and they have normal hearing and visual acuity, no history of chronic disease, regular attendance in the class and there is a significant discrepancy between their potential or ability and actual achievement.

\section{FACTORS RELATED TO LEARNING DISABILITIES: OVERVIEW OF PAST EFFORTS}

Although actual causes of learning disability can never be known, a variety of suspected causes for learning disabilities have been proposed. A brief review of the past studies reveal that etiological factors related to learning disabilities fall generally into three groups: organic and biological, genetic, and environmental.

Learning disability may be caused by slight brain damage. However, research has not shown a direct cause and effect relationship between the two. In other words, there is as yet no solid evidence to indicate that a learning disabled child necessarily has any brain injury or malfunction. Learning-disabled children don't show medical evidence of brain damage (Boshes \& Myklebust, 1964). William and Oransky (1980) think that if the child doesn't learn, it is really no one's fault; he has brain injury that prevents him from learning.

Some researchers claim that biochemical factors within a child's body are the cause of learning disabilities. Scientists are also investigating other biochemical factors, such as the effect of food coloring as possible causal agents. In a comprehensive review of diet related studies, Spring and Sandoval (1976) concluded that there is a little evidence in support of this cause. 
TRIBHUVAN UNIVERSITY JOURNAL, VOL. XXIV, NO. 1,

Cott (1972) hypothesize that learning disabilities can be caused by the inability of a child's bloodstream to synthesize a normal amount of vitamins. Kersher, Hawks, and Gekin (1977) performed an experiment to test the effect of megavitamin therapy with learning disabled children. Their results show that huge doses of vitamins did not improve the performance of learning disabled children. Learning disabilities tend to run in families, but whether this is due to genetic factors or similar learning environments is yet to be determined (Hallahan \& Kaffman, 1980).

Environmental causes are hard to pinpoint, although it appears that children from ghetto areas tend to exhibit more learning problems. Poor quality of teaching can be another environmental factor contributing to academic difficulties (Hallahan \& Kauffman, 1994). Supporting this argument Lovitt (1978: 169) quotes "a condition that might contribute to a learning disability is poor instruction. Although many children are able to learn in spite of poor teachers and inadequate techniques, others are less fortunate. Some youngsters who have experienced poor instruction in the early grades never catch up with their peers." In the word of Engellmann (1977: 46-47) perhaps 90 percent or more of the children who are labeled learning disabled exhibit a disability not because of anything wrong with their Perception, synapses, or memory, but because they have been seriously mistaught. Learning disabilities are made, not born Lovitt (1978) cities that many children with learning problems have behavior disorders and lack of motivation is another contributing factors of Learning disabilities.

According to McLoughlin, 1985 environmental factors might be involved in the case of Learning disabilities. Poor nutrition, health, and safety can precipitate these problems; as can inadequate linguistic and cognitive models in the home. Further, he pointed outs that socio-cultural factors that do not reinforce values for education, regular school attendance, work and study habits, and other supportive skills may create more difficulty for the LD Person. The lack of consistent, appropriate education, might also be at fault (McLonghlin, 1985). The conditions mentioned above are expected to be more prevalent and affecting adversely in rural than in urban areas.

From the review of the literature it is seen that most of the studies have been conducted in USA and Europe. No study done either in Nepal or in India could not been identified for review. In the light of the above consideration, this study was conducted to investigates the factors related to learning disabilities in mathematics among primary school students.

\section{METHOD AND PROCEDURE}

\section{SAMPLE}

The sample for the study consisted of 104 CLDM of grade-V identified from among 1154 grade-V students studying in 29 rural and 15 urban schools of central region of Nepal (Pandit, 1992). Table 1 presents the sample for the study.

Table-1: Number of Learning Disabled students in Mathematics in the Sample

\begin{tabular}{|l|l|l|l|l|l|} 
Age/sex & Boys & Boys & Girls & Girls & Total \\
\hline
\end{tabular}


FACTORS AFFECTING LEARNING DISABILITIES

\begin{tabular}{|c|c|c|c|c|c|}
\hline & (Rural) & (Urban) & (Rural) & (Urban) & \\
\hline $11+$ & 7 & 5 & 5 & 2 & 19 \\
\hline $12+$ & 8 & 15 & 9 & 8 & 40 \\
\hline $13+$ & 5 & 6 & 3 & 9 & 23 \\
\hline $14+$ & 3 & 9 & 3 & 7 & 22 \\
\hline Total: & $\mathbf{2 3}$ & $\mathbf{3 5}$ & $\mathbf{2 0}$ & $\mathbf{2 6}$ & $\mathbf{1 0 4}$ \\
\hline
\end{tabular}

INSTRUMENT

The students' bio-data Performa (SBP) was the main instrument of the study. It was developed by the investigator and was divided into three parts. Specifically, the first part of the BSP consisted of the general information of students related to age, sex, and other personal details.

Second part of the BSP was related to study habits, health condition, parental motivation for study and their behavior towards them, socio-economic status of parents, size of the family structure, housework, assistance for study, teachers behavior to them.

Third part of the BSP sought the educational information, for example, regularity in class, classroom participation, doing homework, etc. in school and at home.

\section{DATA COLLECTION}

The tool for the study was administered individually on each student selected during regular class time in September 1991 to- December 1991. Educational information of each student was collected from class teacher and school record.

\section{STATISTICAL TECHNIQUES USED}

The collected data were analyzed by using percentage.

\section{MAJOR FINDINGS}

1. Self-study habits of the student directly affected to learning disabilities in mathematics. About 44\% LDs studied less than two hours and scored average $38 \%$ marks in their final examination. About 56\% CLDM used to study more than two hours and scored average $45 \%$ in their achievement test.

2. Socio-economic status of the parents had adversely affected to the LDs. 46.87 percent LDs were from very low-income groups and 50\% were from very high-income groups and $43.38 \%$ students were from average income groups. It shows that students from very low-income group and very high-income groups had comparatively more CLDM than from those of average income groups (34.38\%).

3. Parental behavior showed adversely affected the development of CLDM of the individual. Only about $56 \%$ had normal behavior to learning 
TRIBHUVAN UNIVERSITY JOURNAL, VOL. XXIV, NO. 1,

disabled children and $12.5 \%$ parents were apathetic and $31.3 \%$ were extremely dotting behaviors to their children.

4. Most of the girls replied that, they have to work at home for two to four hours per day in average. Where as the boys neglected the question.

5. Most of the CLDM (86\%) responded that they had to study themselves, except a few number of them (14\%) were lucky enough to have educated superiors in their family to help in their education.

6. Size of family played a vital role in CLDM. About $18 \%$ CLDM were from small family having less than five members. 40\% CLDM were from big family having more than 9 members. Remaining CLDM were from medium family.

7. The mathematics teachers of learning disabled children reported that most of them (78\%) were regular in mathematics class, they also participate in the class work but they cannot translate their knowledge in examination.

8. Teacher neglects these groups of children. Their behavior towards the CLDM is not motivating to learn and apathetic.

9. The location of school and quality of instruction is related to the cause of learning disabilities in mathematics.

\section{CONCLUSIONS AND RECOMMENDATIONS}

1. Self-study habit, socio-economic status of students and their parental behavior had affected to the learning disabilities in mathematics. Most of the learning disabled children came from medium and larger size families.

2. Educational planner in Nepal, concerned with the promotion of quality of education should consider making some special education provision for CLDM.

3. The choice of the type of educational provision, that the educational planners may consider, depends upon the availability of the resources. However, it is suggested that any student who fails to make a normal progress in school mathematics should be suspected to have CLDM should be given the remedial instruction with encouragement for study.

4. As the finding of this study suggest that girls are more LDS than boys, it may be due to the reasons that the girls have to do more work at home than boys, due to the parents' negative behavior to them. It is obvious that better teaching helps in reduction of learning disabilities.

5. Proper arrangement of instruction should be made for learning disabled children at both rural and urban areas. In urban area, teachers have to remain very cautious and conscious in dealing with CLDM, as they are more susceptible to be categorized. 


\section{FACTORS AFFECTING LEARNING DISABILITIES}

\section{SUGGESTIONS FOR FURTHER RESEARCH}

From the findings of this study a number of suggestions and recommendations can be made for undertaking further researches in this area.

1. The present study was based on a sample of 104 CLDM of central region of Nepal. This study must be replicated in other region of Nepal. Hence, only through a series of such research a generalization about the actual causes of learning disabilities in mathematics in Nepal could be made.

2. As this study revealed the cause of learning disabilities in mathematics of grade- $V$ students only, further research should be undertaken to study learning disabilities in other grades and in other subjects of instruction.

3. The scope of investigation may be extended to apply to specific age groups, and comparative sex-wise studies of leading disabilities should be done.

4. On the contrary the individual difference of personalities should be examined, as powerful factor of underachievement and the researchers must handle with care.

5. It is suggested that selection of the questionnaire may be done more scientifically and the instrument could be refined.

6. Learning disabilities might exist in socially backward (low cast), economically backward (low socio-economic status, to morally backward, to educationally backward groups. Further research should be done for these groups students.

\section{WORKS CITED}

Boshes, B. \& Myklebus, H. (1964). "Minimal brain damage in children" in C.D. Mercer (ed.). Children and Adolescents with Learning Disabilities. Columbus Oh: Charles E. Merrill.

Clements, S. (1966). Minimal brain dysfunction of in children: Terminology and Identification. Phase one of the Three phase Project, Washington, D.C.: US Department of the Health, Education and Welfare.

Cott (1972). Quoted in Heward, L. William OrlanskY D. Michael (ed.). Exceptional Children. Charles Merril Publishing Company, p. 85.

Cruickshank, W.H. (1985). Education of exceptional children and youth. Englewood Cliffs: Printice Hall Inc.

(1972). "Some issues facing the field of learning disabilities." Journal of Learning Disabilities. 5:380-388, May.

Educational Commission Report, Nepal (1992). Kathmandu: National Education Committee.

Educational Statistics of of Nepal (1995). Kathmandu: MOEC, HMG. 
TRIBHUVAN UNIVERSITY JOURNAL, VOL. XXIV, NO. 1,

Engelmann, S.E. (1977). "Sequencing cognitive and academic tasks." in R.D. Kneedler \& and S.C. Traver (eds.). Changing perspective in special education. Columbus, Ohio: Charles E. Merrill.

Hallahan, D.P. \& Cruickshank, W.M. (1973). Psycho-educational foundatio of learning disabilities. Englewood Cliff: Prentice Hall.

Johnson \& Morasky, R.L. (1989). Learning disabilities. Boston: Allyn and Bacon, Inc.

Kesher, Hawks \& Gekin (1977). Quoted in Heward, L. William \& Orlansky D. Michael (ed.). Exceptional Children. Charles Merril Publishing Company, p. 85.

Kirk, S.A. (1963). "Behavioral diagnosis and remediation of learning disabilities." Proceedings of the Conference on Exploration into the problems of the Perceptually Handicapped Child. First Annual Meeting, April 6.

(1972). Educating exceptional children. Boston: Houghton Mifflin.

Lerner, J.W. (1976). Children with learning disabilities ( $2^{\text {nd }}$ ed.). Boston: Houghton Mifflin.

Lovitt, T.C. (1978). "Applied behavior analysis and learning disabilities- specific research recommendation, and suggestions for practitioners." Journal of Learning Disabilities. No. 8, pp. 504-518.

Mercer, C.D. (1979 ed.; 1985 ed.). Children and adolescent with learning disabilities, Colombus: $\mathrm{OH}$, Charles E. Merrill.

Pandit, R.P. (2000). "A model for the identification of learning disabilities in mathematics." Shikshak Journal. Vol. 3, Kathmandu: Mahendra Ratna Campus, pp. 11-17.

(1995). Incidence of learning disabilities in mathematics in developing countries- A case study of Nepal. A seminar paper, presented in XXIX Annual Conference of Indian Association of Teacher Educators held from December 2729, 1995 at Regional Institute of Education, Bhubaneswor, India

(1992). A Study of learning disabilities in mathematics among grade-V primary school children in central region of Nepal. Ph.D. Thesis, submitted to BHU, India.

William, H.L. \& Orlansky, D.M. (1980). Exceptional children. US: Charles Merrill Publishing Company. 